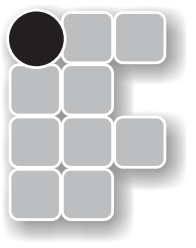

DESEMPENHO AGRONÔMICO E COMPORTAMENTO

\title{
DE CULTIVARES DE MORANGUEIRO QUANTO À MANCHA-DE-PESTALOTIOPSIS E ÀS PODRIDÕES DOS FRUTOS
}

Joaquim Gonçalves de Pádua ${ }^{1}$

Jaime Duarte Filho ${ }^{2}$

Thaís Helena de Araújo ${ }^{3}$

Samuel Guilherme Pereira ${ }^{4}$

Ezequiel Lopes do Carmo ${ }^{5}$

Francisco Eduardo de Carvalho Costa ${ }^{6}$

Mário Sérgio Carvalho Dias

\section{Resumo}

O cultivo do morangueiro desempenha uma importante função econômica e social, contribuindo para a geração de renda e melhoria da qualidade de vida, além da fixação do homem no campo. Embora as condições climáticas na região sul de Minas Gerais sejam favoráveis ao desenvolvimento da cultura, contribuem também para a maior incidência de doenças, sendo a mancha-de-pestalotiopsis uma das principais doenças fúngicas que pode causar sérios prejuízos aos produtores de morango. Objetivou-se, por meio deste trabalho, avaliar o desempenho agronômico e o comportamento de nove cultivares de morangueiro quanto à mancha-depestalotiopsis e podridões dos frutos. $O$ experimento foi desenvolvido sob casa de vegetação, delineado em blocos ao acaso, com quatro repetições. Foi feita a inoculação das plantas com isolados do patógeno e a severidade da doença foi medida utilizando a escala descritiva. A avaliação da doença foi realizada a cada dois dias por um período de 16 dias. Avaliou-se também a produção de frutos comerciais e de frutos refugos por planta, num total de nove colheitas, o percentual de frutos por tamanho e o percentual de frutos com podridão por Botrytis, Rhyzopus e outros patógenos. Dover e Tudla apresentaram plantas com maior resistência à mancha-depestalotiopsis, porém sem a melhor performance na produção de frutos, sendo que Dover apresentou maior percentual de frutos atacados por Rhyzopus e outros patógenos. Camarosa, embora com bom desempenho produtivo, apresentou plantas com maior sensibilidade à mancha-de-pestalotiopsis. Albion apresentou maior percentual de frutos com Botrytis. As cultivares Ventana, Oso Grande e Camino Real apresentaram melhor desempenho agronômico em relação à produção, qualidade dos frutos e reação à mancha-de-pestalotiopsis.

Palavras-Chave: Fragaria x ananassa Duch. Doenças. Pestalotiopsis longisetula. Produção.

\section{Introdução}

O cultivo do morangueiro, na região Sul de Minas, desempenha importante função econômica e social por movimentar um grande volume de recursos e demandar mão de obra que, na maioria das vezes é familiar,

${ }^{1}$ EPAMIG - Núcleo Tecnológico de Batata e Morango, pesquisador. E-mail: padua2008@gmail.com. (35) 3421-3791. Avenida Pref. Tuany Toledo, 470, Fátima I, Pouso Alegre, MG, Brasil CEP 37550-000.

${ }^{2}$ CATI - Casa da Agricultura de Conchas, extensionista. E-mail: jaime.duarte@cati.sp.gov.br. (14) 3882-4422. Rua Coronel Virgílio F. de Queiroz, 248, Conchas, SP, Brasil.CEP 18570-000.

${ }^{3}$ ESALQ/USP - Departamento de Produção Vegetal, pesquisadora de doutorado, bolsista do CNPq. E-mail: tharaujo@usp.br. (19) 3371-0378. Avenida Pádua Dias, 11, Piracicaba, SP, Brasil. CEP 13418-900, Caixa Postal 09.

${ }^{4}$ UNIVÁS - Departamento de Biologia, biólogo. E-mail: samuelgpereira@yahoo.com.br. (35) 3421-3791. Avenida Pref. Tuany Toledo, 470, Fátima I, Pouso Alegre, MG, Brasil, CEP 37550-000.

${ }^{5}$ IFMT - Campus Campo Novo do Parecis, professor pesquisador. E-mail: ezequielcerat@gmail.com. (65) 8107-3307. Rodovia MT 235 Km 12, s/n, Campo Novo do Parecis, MT, Brasil, CEP 78360-000.

${ }^{6}$ Instituto Nacional de Telecomunicação - Curso de Engenharia Biomédica, professor pesquisador. E-mail: costafec@yahoo.com.br. (35) 8845-3555. Avenida João de Camargo, 510, Santa Rita do Sapucaí, MG, Brasil, CEP 37540-000.

EPAMIG - Núcleo Tecnológico de Batata e Morango, pesquisador. E-mail: mariodias@epamig.br. (35) 3421-3791. Avenida Pref. Tuany Toledo, 470, Fátima I, Pouso Alegre, MG, Brasil, CEP 37550-000. 
contribuindo para a geração de renda e melhoria da qualidade de vida, além da fixação do homem no campo (DIAS; SIMÕES, 2009). Este desempenho faz com que a cultura consolide-se ano a ano, predominantemente em pequenas propriedades, impulsionada ainda pelas condições climáticas favoráveis e pela localização privilegiada em relação aos grandes centros consumidores (DUARTE FILHO, 2006). Em contrapartida, as condições climáticas favoráveis podem se tornar um fator limitante à produção por favorecer também os patógenos, aumentando a incidência de doenças ao longo do ciclo.

Dentre as principais doenças fúngicas, que incidem sobre o morangueiro, encontra-se a mancha-depestalotiopsis e as podridões dos frutos. A mancha-de-pestalotiopsis foi primeiramente observada em Israel, em frutos armazenados, e posteriormente, sob condições de campo, em cultivos comerciais de Israel, dos EUA e da Índia (EMBABY, 2007). No Brasil, os primeiros ataques do fungo foram observados em 2004, em viveiro de mudas, e em 2005 em lavouras comerciais, no estado do Espírito Santo (COSTA; VENTURA, 2006) e posteriormente em Minas Gerais, São Paulo, Paraná e Distrito Federal (REIS e COSTA, 2011).

O fungo causador da mancha-de-pestalotiopsis pode incidir sobre todas as partes da planta como folhas, pecíolos, estolões e raízes, e desde a produção de mudas, causando a desfolha, até a fase produtiva, atacando os frutos (CAMILI et al., 2002; DUARTE FILHO, 2006), reduzindo a massa média e sólidos totais do morango e também infectando frutos de outras espécies como o pêssego e o tomate (EMBABY, 2007).

Algumas tentativas de controle da pestalotiopsis em morangueiro sob condições de campo foram realizadas através da aplicação do óleo de Melaleuca sp. e fungicidas, porém não foram totalmente eficientes (PEREIRA et al. 2011). Ainda não há formas efetivas de controle desta doença e sua disseminação está ocorrendo de maneira preocupante (DUARTE FILHO, 2006).

As podridões pós-colheita são um dos principais problemas em todas as regiões onde se cultiva morango no Brasil (LOPES, 2011). São escassas as informações a respeito dos agentes causais, bem como as estratégias de manejo das podridões do campo à pós-colheita.

Dentre os patógenos fúngicos que causam podridão em frutos de morango na pós-colheita no Brasil destacam-se Botrytiscinerea e Rhizopusstolonifer, além de outras espécies com menor frequência como Colletrotichum spp., Rizoctoniasolani e Phytophthoraspp (ZAMBOLIM; COSTA, 2006). Além disso, Lopes (2011) avaliando as condições propícias ao desenvolvimento dos principais agentes causadores dessas podridões em frutos de morango observou que a incidência foi variável ao longo do ano, sendo os mais frequentes B. cinerea (36,3\%), R. stolonifer (34,9\%) e Geotrichumcandidum $(31,1 \%)$.

O mofo cinzento $(B$. cinerea) é um dos principais problemas mundiais na pré e pós-colheita do morango (PAGNAN, 2013). Na Flórida, EUA, é a doença que mais causa redução na produção de morango, mesmo com aplicações regulares de fungicidas (LEGARD et al., 2005). No Brasil constitui-se num dos principais problemas em pós-colheita do morango por causar podridão dos frutos, podendo atacar também as folhas, pecíolos, caule, botões florais e pétalas (FORTES, 2005). 0 mofo cinzento ataca mais de 300 espécies de plantas e pode afetar frutos em qualquer estádio de desenvolvimento, porém, é mais comum em frutos maduros ou em fase de amadurecimento (REIS; COSTA, 2011). A doença é favorecida por temperaturas amenas e alta umidade (FORTES, 2005), sendo que as maiores perdas são observadas após os períodos de chuvas que antecedem a colheita (COSTA; VENTURA, 2006). O cultivo sob túneis reduz significativamente a incidência de $B$. cinerea quando comparado com o cultivo a campo aberto, porém onera o custo de produção (LEGARD et al., 2005). Portanto, o controle eficaz de Botrytis deve ser feito com a combinação de métodos culturais e/ou químicos, principalmente com utilização de cultivares resistentes ou tolerantes.

A podridão de Rhyzopus ( $R$. stolonifere $R$. nigricans) ocorre principalmente em pós-colheita, sendo mais severa durante o armazenamento e a comercialização, mas pode também ocorrer ainda no campo, em qualquer estádio de desenvolvimento do fruto (FORTES, 2005). Os sintomas da doença são podridão mole e aquosa dos frutos e o desenvolvimento de mofo sobre os frutos, inicialmente branco, evoluindo para uma cor preta (REIS; COSTA, 2011), ocorrendo com maior intensidade em embalagens que contêm frutos muito maduros (COSTA; VENTURA, 2006). Como medida de controle é recomendado evitar que o fruto entre em contato com o solo utilizando cobertura plástica ou mulching nos canteiros, manusear cuidadosamente os frutos durante a colheita e pós-colheita evitando ferimentos e evitar condições de alta umidade e temperaturas acima de $10^{\circ} \mathrm{C}$ (DIAS; COSTA; CANUTO, 2007; FORTES, 2005).

O conhecimento das doenças do morangueiro e as táticas de controle a serem adotadas são um desafio para que a cultura mantenha sua importância econômica e social e que seja sustentável por vários anos, atendendo aos princípios da produção integrada (DUARTE FILHO, 2006).

Nos últimos anos, inúmeras cultivares estão sendo introduzidas na região Sul de Minas sem avaliações prévias, podendo resultar em escolha errônea da cultivar e grandes prejuízos ao produtor. Portanto, essas 
avaliações são importantes porque apenas uma cultivar pode apresentar diferentes comportamentos conforme a região e o manejo adotado, resultando em diferentes produtividades e qualidades do produto final (DUARTE FILHO, 2006).

Este trabalho teve como objetivo avaliar o desempenho agronômico e o comportamento de cultivares de morangueiro na região sul de Minas Gerais e a reação destas à mancha-de-pestalotiopsis e às podridões dos frutos.

\section{Material e métodos}

O ensaio foi conduzido no período de maio a novembro de 2010, na área experimental da UNIVÁS, Pouso Alegre-MG, em casa de vegetação do tipo capela não-climatizada. Os tratamentos foram compostos das cultivares Albion, Camarosa, Camino Real, Dover, Festival, Oso Grande, Tudla, Ventana e Verão. O delineamento adotado foi o de blocos ao acaso, com quatro repetições. Cada parcela experimental foi constituída por oito plantas sendo duas plantas por vaso, totalizando 32 plantas avaliadas por cultivar. Foi utilizada a mistura previamente esterilizada de solo e substrato na proporção 2:1 e adição de 230 g do adubo formulado 04-14-08 (N-P-K) em vaso com capacidade de 5 litros.

A partir dos noventa dias após o transplantio, fez-se adubações semanais de cobertura com a solução de Hoagland a $10 \%$, aplicando $50 \mathrm{~mL}$ por vaso, como forma de suplementação mineral. 0 isolado de Pestalotiopsislongisetula foi multiplicado em meio de cultura batata dextrose agar (BDA), constituído de 40g de batata, $15 \mathrm{~g}$ de agar e $15 \mathrm{~g}$ de dextrose para $1 \mathrm{~L}$ de água destilada e esterilizada.

Para realização do teste, o fungo foi cultivado por sete dias em meio de cultura BDA, à temperatura de $28^{\circ} \mathrm{C}$. O preparo do inóculo foi obtido adicionando-se $10 \mathrm{~mL}$ de água destilada esterilizada na colônia formada pelo fungo. Com o auxílio de uma alça de platina, previamente flambada, foi raspada toda a superfície colonizada resultando no desprendimento dos conídios da cultura. A suspensão conidial formada foi filtrada em camada dupla de gaze esterilizada. Essa suspensão foi calibrada para a concentração de $1 \times 10^{6}$ conídios. $\mathrm{mL}^{-1}$, utilizando um hematocitômetro do tipo Neubauer. As folhas e pecíolos sadios das cultivares foram lesionados com um conjunto de agulhas e foram inoculados com a suspensão conidial contendo o fungo Pestalotiopsis/ongisetula. 0 controle foi realizado com água destilada esterilizada. As plantas foram mantidas em câmara úmida por 24 horas e a severidade da doença foi medida utilizando a escala descritiva com dez notas (KANUFT et al., 1988).

A avaliação da doença foi realizada a cada dois dias por um período de 16 dias. Foi feita também a avaliação da produção de frutos comerciais e de frutos refugos por planta, num total de nove colheitas. Da produção comercial foi feita a determinação do percentual de frutos por classe de tamanho em Extra (> $15 \mathrm{~g})$, Primeira, 6 a 15 g, e Segunda (< 6 g) (LIMA, 1999). Da produção de frutos refugos foi feita a avaliação do percentual de frutos com podridões (Botrytis, Rhizopus e outras podridões). Os resultados foram submetidos à análise de variância e as médias dos tratamentos foram comparadas pelo teste Tukey a $5 \%$ através do software SISVAR.

\section{Resultados e discussão}

Na tabela 1 são apresentados os valores de produção total de frutos por planta e a massa média dos frutos. A cultivar Dover produziu maior número de frutos por planta, seguida pelas cultivares Ventana, Oso Grande e Camarosa. Entretanto, a cv. Dover apresentou frutos com menor massa média, com valores inferiores às cvs. Camino Real, Ventana e Albion. Por outro lado, as cvs. Albion e Camino Real produziram menor número de frutos por planta e desse modo, na produção total de massa fresca por planta, a cv. Ventana foi superior às demais, se igualando apenas à cv. Oso Grande. 
Tabela 1. Produção total de frutos por planta (número e massa) e massa média de frutos. Pouso Alegre, EPAMIG, 2011.

\begin{tabular}{lrlrlrl}
\hline & \multicolumn{5}{c}{$\begin{array}{c}\text { Produção } \\
\text { total de } \\
\text { frutos por } \\
\text { planta }\end{array}$} \\
Cultivares & Número & Massa (g) & $\begin{array}{c}\text { Massa } \\
\text { média de } \\
\text { frutos (g) }\end{array}$ \\
\hline Albion & 11,93 & c & 137,00 & bcd & 11,33 & abc \\
Camarosa & 17,50 & b & 157,34 & bc & 9,29 & bcd \\
Camino Real & 12,13 & c & 165,21 & bc & 13,54 & a \\
Dover & 22,93 & a & 154,00 & bc & 6,75 & d \\
Festival & 10,90 & cd & 78,59 & cde & 7,11 & d \\
Oso Grande & 18,40 & b & 179,21 & ab & 9,78 & bcd \\
Tudla & 5,25 & e & 33,59 & e & 6,98 & d \\
Ventana & 20,90 & ab & 254,09 & a & 12,17 & ab \\
Verão & 7,06 & de & 59,81 & de & 8,30 & cd \\
\hline Média geral & 14,12 & & 135,43 & 9,47 & \\
F (trat.) & 45,03 & $* *$ & 13,89 & $* *$ & 12,31 & $* *$ \\
DMS (5\%) & 4,39 & 87,80 & 3,35 & \\
C.V. (\%) & 12,94 & 26,96 & 14,73 & \\
\hline
\end{tabular}

Médias seguidas pela mesma letra nas colunas, não diferem entre si pelo teste de Tukey (** $p<0,01 \%$ ).

Resultados semelhantes foram obtidos por Calvete et al. (2008), sob condições de cultivo protegido, e por Castro et al. (2003) no sistema de cultivo orgânico a campo, que observaram maior número de frutos por planta e frutos com menor massa média para a cultivar Dover. De acordo com Duarte Filho et al. (2003), a cultivar Dover tem como característica o início precoce da produção de frutos e a maior concentração desta até meados do ciclo, quando então passa a ter uma produção de frutos com tamanho e massa abaixo do padrão comercial.

A cultivar Ventana, que apresenta como característica principal a produção de frutos grandes, com maior tamanho e massa média (OLIVEIRA; SCIVITTARO, 2011), superou todas as demais e com relação à massa de frutos por planta apresentou plantas mais produtivas igualando apenas à cultivar Oso Grande, a qual segundo Balbino et al. (2006), tem como característica a alta proporção de frutos graúdos. Pereira et al. (2013) também observaram maior produtividade para a cv. Oso Grande, independente da época de plantio, em cultivo a campo, nas condições de Bom Repouso-MG.

Oliveira, Scivittaro e Finkenauer (2008), avaliando a cv. Camino Real em comparação com as cvs. Aromas e Camarosa em cultivo sob condições protegidas no município de Pelotas-RS, observaram que a cv. Camino Real produziu menor número de frutos por planta e que os frutos foram maiores e com maior massa média, resultados estes que corroboram aqueles obtidos no presente trabalho (tabela 1).

As cultivares Festival, Tudla e Verão foram menos produtivas tanto em número como em massa total de frutos (tabela 1). Resultados semelhantes foram observados por Pereira et al. (2013), que obtiveram maior número e massa de frutos na cv. Oso Grande em relação à cv. Festival, nos plantios realizados de junho a agosto, em cultivo a campo, nas condições de Bom Repouso-MG. Calvete et al. (2008) também observaram resultados semelhantes aos do presente trabalho para número e massa de frutos por planta com a cv. Tudla, entretanto obtiveram frutos com elevada massa média, de excelente valor comercial, o que não foi observado no presente estudo. Os resultados observados para a cv. Tudla, no presente trabalho, são discordantes daqueles observados por Shaw (2004), que a descreve como bastante produtiva e com frutos grandes.

As cultivares Tudla e Verão apresentaram o menor percentual de frutos comerciais por planta (tabela 2) quando comparadas às demais cultivares, entretanto não diferenciaram destas com relação à massa dos frutos, à exceção das cultivares Camarosa, Festival e Oso Grande que apresentaram frutos comerciais com massa superior a cultivar Verão. 
A cultivar Festival destacou-se na produção de frutos comerciais por planta, superando as cultivares Tudla e Dover no número, e a cultivar Verão no número e massa de frutos, não diferindo das demais. "Tudla" e "Verão" também produziram o maior percentual do número e massa de frutos refugos, igualando nesta última característica à cultivar Dover (tabela 2). Portanto o tamanho e o número de frutos estão diretamente relacionados à capacidade de produção do morangueiro (OLIVEIRA; BONOW, 2012). Entretanto, as diferenças observadas entre as produtividades obtidas no presente estudo e nos demais trabalhos eram esperadas, pois alterações climáticas e de foto-período podem alterar a produtividade de uma mesma variedade dentro de uma microrregião (RADIN et al., 2011), justificando a necessidade de informações técnicas específicas para o sul de Minas Gerais.

Tabela 2. Percentual de frutos comerciais e refugos sobre a produção total. Pouso Alegre, EPAMIG, 2011.

\begin{tabular}{|c|c|c|c|c|c|c|c|c|}
\hline \multirow[t]{2}{*}{ Cultivares } & \multicolumn{4}{|c|}{$\begin{array}{l}\text { Porcenta- } \\
\text { gem de } \\
\text { frutos } \\
\text { comerciais }\end{array}$} & \multicolumn{4}{|c|}{$\begin{array}{l}\text { Porcenta- } \\
\text { gem de } \\
\text { frutos } \\
\text { refugos } \\
\end{array}$} \\
\hline & \multicolumn{2}{|c|}{ Número } & \multicolumn{2}{|c|}{ Massa (g) } & \multicolumn{2}{|c|}{ Número } & \multicolumn{2}{|c|}{ Massa (g) } \\
\hline Albion & 72,12 & $a b$ & 81,24 & $a b$ & 27,88 & bc & 18,75 & c \\
\hline Camarosa & 79,23 & $a b$ & 81,78 & $a$ & 20,76 & bc & 18,21 & c \\
\hline Camino Real & 74,83 & $a b$ & 79,04 & $a b$ & 25,11 & bc & 20,95 & $\mathrm{bc}$ \\
\hline Dover & 67,37 & $b$ & 69,95 & $a b$ & 32,63 & b & 30,04 & $a b$ \\
\hline Festival & 80,99 & a & 82,96 & $a$ & 19,00 & c & 16,24 & C \\
\hline Oso Grande & 79,01 & $a b$ & 83,56 & a & 20,98 & $b c$ & 16,43 & C \\
\hline Tudla & 46,24 & c & 66,62 & $a b$ & 53,75 & a & 38,18 & a \\
\hline Ventana & 75,45 & $a b$ & 67,13 & $a b$ & 24,54 & $b c$ & 22,86 & $\mathrm{bc}$ \\
\hline Verão & 53,67 & $c$ & 61,95 & $\mathrm{~b}$ & 46,32 & $\mathrm{a}$ & 38,05 & $a$ \\
\hline Média geral & 69,88 & & 74,91 & & 30,11 & & 24,41 & \\
\hline F (trat.) & 21,76 & ** & 4,29 & $* *$ & 21,81 & $* *$ & 16,06 & ** \\
\hline DMS (5\%) & 12,53 & & 19,53 & & 12,52 & & 10,58 & \\
\hline C.V. (\%) & 7,46 & & 10,84 & & 17,30 & & 18,03 & \\
\hline
\end{tabular}

Médias seguidas pela mesma letra nas colunas, não diferem entre si pelo teste de Tukey (** $p<0,01 \%$ ).

Na Figura 1 é apresentada a produção de frutos comerciais, expressa em gramas por planta, e o percentual de frutos por classe de tamanho em relação à produção comercial. A cultivar Ventana destacou-se quanto a produção comercial perante as cultivares Albion, Tudla, Dover, Festival e Verão, mas não diferiu das demais. A cultivar Camino Real apresentou maior percentual de frutos tipo Extra e destacou das demais, não diferenciando das cultivares Ventana e Albion. Não foi observada diferença significativa entre as cultivares para produção de frutos de Primeira. A cultivar Dover produziu maior percentual de frutos de Segunda, diferindo apenas da cultivar Camino Real e da cultivar Ventana, não diferenciando das demais. Chandler et al. (2005) relataram que uma das principais vantagens da cv. Camino Real refere-se à pequena porcentagem de frutos pequenos produzidos (menos de $1 \%$ com massa inferior a $10 \mathrm{~g}$ ). 


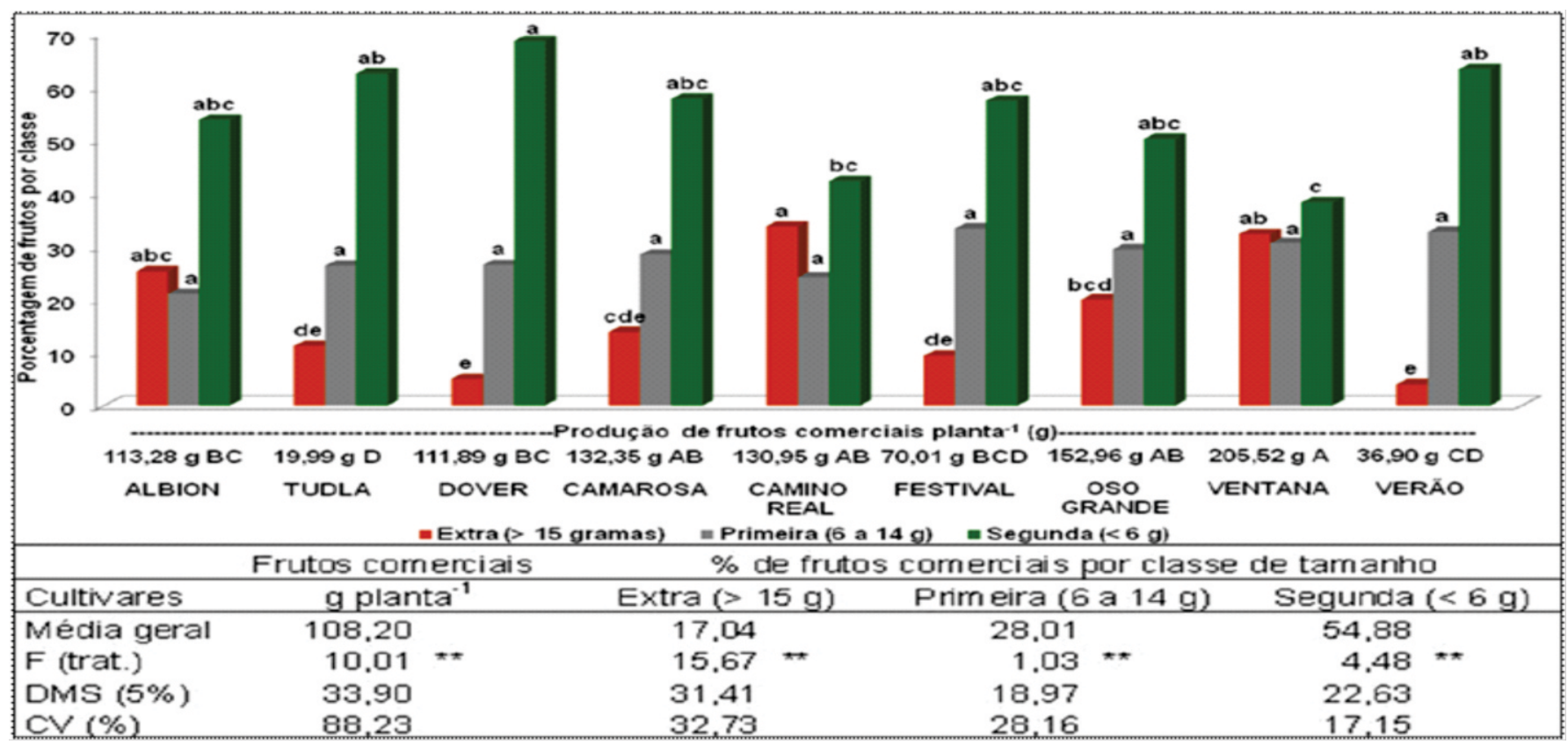

Figura 1. Produção de frutos comerciais (gramas planta ${ }^{-1}$ ) e percentual de frutos por classe de tamanho sobre a produção comercial. Pouso Alegre, EPAMIG, 2011.

Médias seguidas pela mesma letra em cada classe de tamanho e para frutos comerciais, não diferem entre si pelo teste de Tukey $(* * p<0,01 \%)$.

O tamanho dos frutos, que pode ser predeterminado pela massa média dos frutos de padrão comercial, é uma característica importante, pois a maior proporção de frutos grandes agrega maior valor ao produto, reduz o tempo gasto na colheita e embalagem (CONTI et al., 2002).

A adaptabilidade de uma cultivar a uma determinada região produtora é expressa pela interação genótipo-ambiente. A interação entre temperatura e foto-período determina a produtividade e a qualidade do fruto, as quais também são influenciadas pelas condições de solo e pela incidência de pragas e doenças (OLIVEIRA; BONOW, 2012).

Quanto ao comportamento das cultivares à mancha-de-pestalotiopsis, a cv. Camarosa apresentou maior suscetibilidade à mancha-de-Pestalotiopsis na parte aérea das plantas e maior percentual de plantas atacadas pelo fungo, embora não tenha diferido significativamente da maioria das cultivares devido ao elevado coeficiente de variação (Figura 2). As exceções foram as cultivares Dover e Tudla que mostraram resistência ao ataque do fungo e não apresentaram nenhuma planta com desenvolvimento dos sintomas após a inoculação do patógeno (Figura 2).

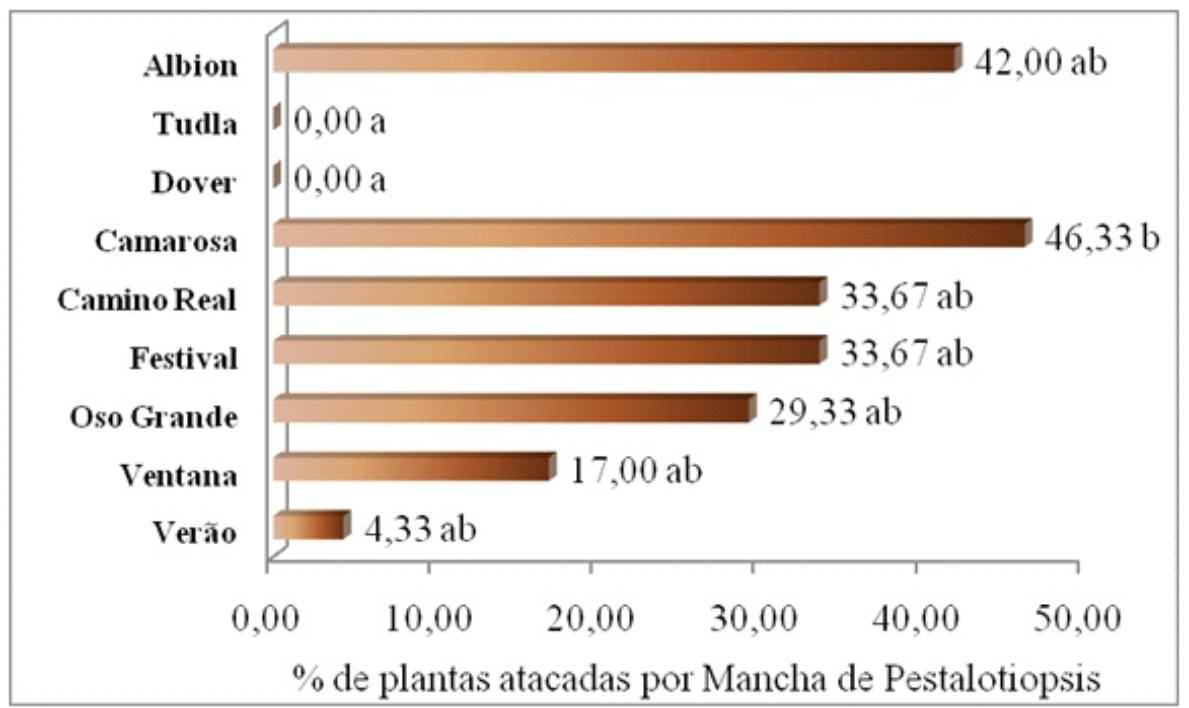

Figura 2. Percentual de plantas atacadas por mancha-de-pestalotiopsis após a inoculação do patógeno. Média geral = 20,63; $F$ (trat.) = 4,68; DMS (5\%)= 43,39; e C.V. $(\%)=71,82$. Pouso Alegre, EPAMIG, 2011. 
A cultivar Dover também apresentou maior resistência à mancha-de-pestalotiopsis nos estados do Espírito Santo e Minas Gerais (COSTA; VENTURA, 2006). Portanto, as cultivares Tudla e Dover apresentam um grande potencial para estudos genéticos visando à resistência das plantas a este fungo. Por outro lado, a cultivar Dover apresentou maior percentual de frutos atacados por Rhyzopussp e outros patógenos (Figura 3B e 3C).

Quanto ao comportamento das cultivares aos agentes causais de podridões nos frutos, as cultivares Albion, Camino Real e Ventana apresentaram maior percentual de frutos com Botrytis, destacando das cultivares Festival, Tudla, Camarosa, Oso Grande e Verão, que apresentaram o menor percentual de frutos com esta podridão (Figura 3A).
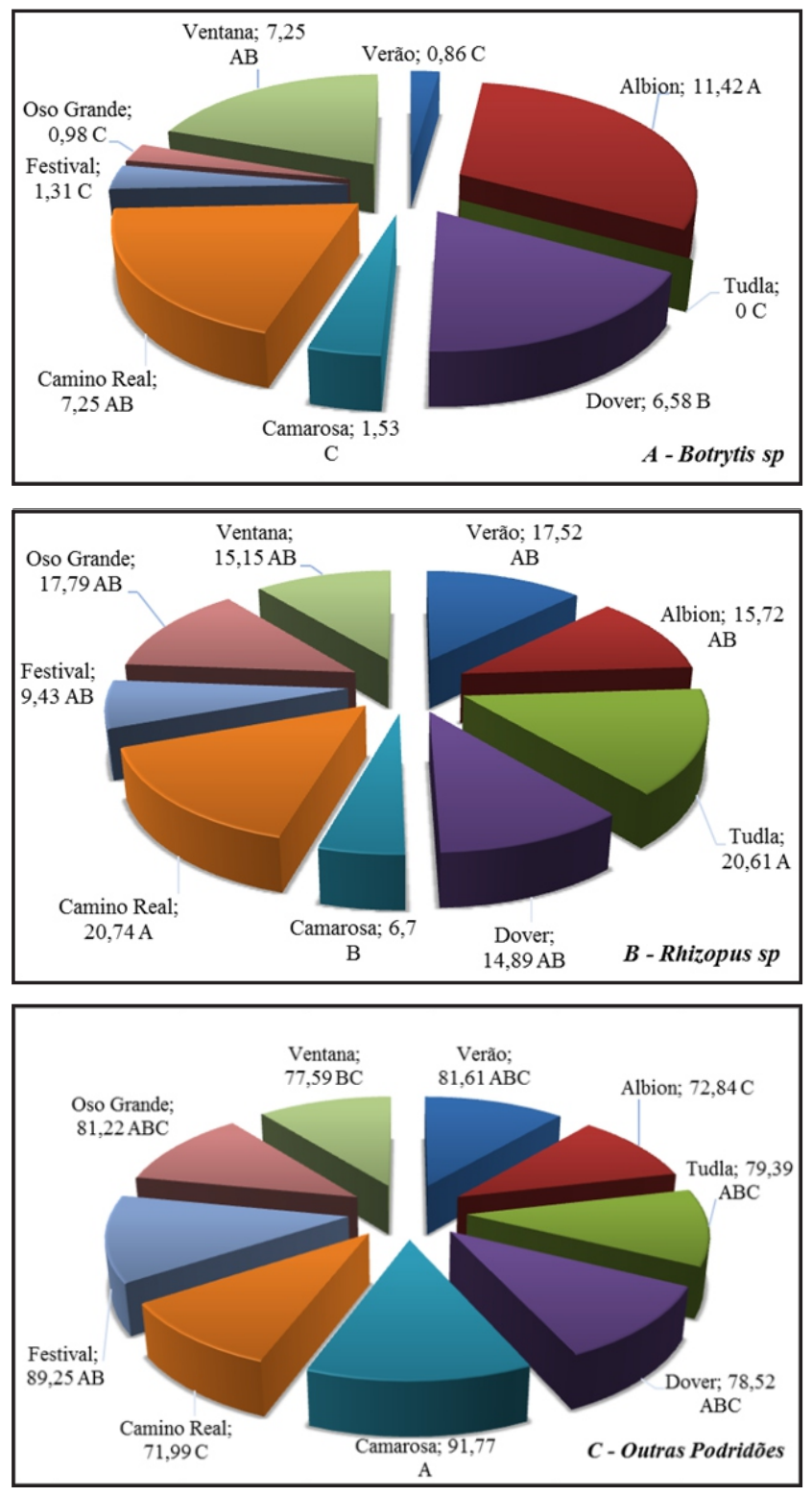

Figura 3. Percentual de frutos atacados por diferentes agentes causais de podridão. Pouso Alegre, EPAMIG, 2011. Médias com mesma letra em cada categoria de doença, não diferem entre si pelo teste de Tukey ( $p<0,05 \%)$.

Tudla e Camino Real apresentaram frutos com maior sensibilidade à podridão por Rhizopussp em comparação à cultivar Camarosa, que teve o menor percentual de frutos atacados pelo fungo (Figura 3B). Resultados semelhantes foram obtidos por Costa e Ventura (2006) na região produtora do estado do Espírito Santo, onde observaram uma maior sensibilidade da cultivar Camino Real ao Botrytis sp e ao Rhizopussp, assim como ocorreu nesse ensaio. A cultivar Festival apresentou tolerância a Botrytis $s p$ conforme observado por Chandler et al. (2000) enquanto foi suscetível a outras podridões.

O uso sucessivo do solo sem a rotação de culturas e o manejo inadequado tem aumentado a quantidade de fungos danosos à cultura do morango. Desse modo, a busca por novas tecnologias tem sido uma constante entre os produtores com o intuito de diminuir os problemas com a cultura (PAGNAN; MONEGAT, 2014). 
Portanto, o uso de cultivares adaptadas à região e tolerantes às principais doenças que incidem sobre o morangueiro, associado ao manejo eficiente, poderão resultar em maior lucratividade, principalmente ao produtor.

\section{Conclusões}

As cultivares Dover e Tudla foram mais resistentes à mancha-de-pestalotiopsis, porém apresentaram menor produção e maior percentual de frutos do tipo segunda, de menor cotação comercial;

A cultivar Camarosa apresentou plantas com bom desempenho produtivo, porém com maior sensibilidade à mancha-de-pestalotiopsis;

As cultivares Ventana, Oso Grande e Camino Real apresentaram plantas com melhor desempenho agronômico em relação à produção e qualidade dos frutos, além de moderada resistência à mancha-depestalotiopsis sendo, portanto, recomendadas para o cultivo no Sul de Minas sob condições protegidas;

As cultivares Dover e Tudla podem ser úteis em programas de melhoramento genético na tentativa de transferir a resistência à mancha-de-pestalotiopsis para materiais com melhor desempenho produtivo e qualidade de frutos.

\section{Agradecimentos}

À FAPEMIG pelo apoio financeiro e ao pesquisador Hélcio Costa, do INCAPER, pelo fornecimento de isolados do fungo Pestalotiopsis longisetula.

\section{Agronomic performance and behavior of strawberry cultivars to Pestalotiopsis and fruit rot}

\section{Abstract}

Strawberry growing plays an important economic and social role, contributing to generate income and improving the quality of life, besides keeping people in the field. Although climate conditions in the southern region of Minas Gerais State are favorable to the development of the culture, it also contributes to higher incidence of diseases, and pestalotiopsis leaf spot is the major fungal diseases that can cause serious damage to strawberry producers. This study aimed to evaluate the agronomic performance and behavior of nine strawberry cultivars of pestalotiopsis leaf spot and rot of fruits. This experiment was developed under greenhouse conditions designed in randomized blocks with four replications. Inoculation of plants was done with isolates of the pathogen and the disease severity was measured using the descriptive scale. The disease was assessed every two days for a period of 16 days. The production of commercial fruit and rejected fruits per plant were also evaluated, in a total of nine collections, as well as the percentage of fruits by size and the percentage of fruit with Botrytis rot, Rhyzopus and other pathogens. Dover and Tudla showed plants with higher resistance to pestalotiopsis leaf spot, but without the best performance regarding fruit production, and Dover showed higher percentage of fruits attacked by Rhyzopus and other pathogens. Although with good productive performance, Camarosa showed plants with higher sensitivity to pestalotiopsis leaf spot. Albion showed higher percentage of fruits with Botrytis. Cultivars Ventana, Oso Grande and Camino Real showed better agronomic performance in relation to production, fruit quality and resistance to pestalotiopsis leaf spot.

Keywords: Fragaria x ananassa Duch. Diseases. Pestalotiopsis longisetula. Production.

\section{Referências bibliográficas}

BALBINO, J. M. S.; ATHAYDE, M. O. ; TEIXEIRA, C. P. ; COSTA, H. ; COSTA, A. F. Tecnologias para produção de mudas e cultivo comercial de morango. In: BALBINO J. M. S. (ed). Tecnologias para produção, colheita e póscolheita de morangueiro. Vitória: INCAPER. 2006. p. 39-56. 
CALVETE, E. O.;MARIANI, F.; WESP, C.L.; NIENOW, A.A.; CASTILHO,T. CECCHETTI, D. Fenologia, produção e teor de antocianicas de cultivares de morangueiro em ambiente protegido. Revista Brasileira de Fruticultura, Jaboticabal-SP, v. 30, n. 2, p. 396-401, 2008.

CAMILI, E. C.; CARBONARY, M.; SOUZA, N. L. CharacterizationofPestalotiopsislongesetula and its pathogenicity in strawberry. SummaPhytopathologica, v. 28, p. 213-214, 2002.

CASTRO, R. L.; CASALI, V.W.D.; BARRELLA, T.; SANTOS, R,H.S.; CRUZ, C.D. Produtividade de cultivares de morangueiro em sistema de cultivo orgânico. Horticultura Brasileira, Brasília, v. 21, n. 2, p. 227-230, 2003.

CHANDLER, C. K. LEGARD, D. E.; DUNINGAN, D. D.; SIMS, C. A.Strawberry Festival"strawberry. HortScience. v. 35, p. 1366-1367, 2000.

CHANDLER, C. K.; SUMLER J. R. J. C.; RONDON, S. Evaluation of strawberry cultivars grownunder a high plastic tunnel in west central Florida. Proceedings of the Florida State Horticultural Society, Tallahassee, v. 118, p. 113-114, 2005.

CONTI, J. H.; MINAMI, K.; TAVARES, F. C. Comparação de caracteres morfológicos e agronômicos com moleculares cultivados no Brasil. Horticultura Brasileira. v. 20, n. 3, p. 419-423, 2002.

COSTA, H.; VENTURA, J. A. Doenças do morangueiro: diagnóstico de manejo. In: BALBINO J. M. S. (ed). Tecnologias para produção, colheita e pós-colheita de morangueiro. Vitória: INCAPER. 2006. p. 39-56.

DIAS, M. S. C.; COSTA, H.; CANUTO, R. S. Manejo de doenças do morangueiro. Informe Agropecuário. Belo Horizonte,v. 28, n. 236, p. 64-77, 2007.

; SIMÕES J. C. Pesquisa leva morango ao Semiárido. Informe Agropecuário.Belo Horizonte: EPAMIG. v. 30, p. 97-107, 2009.

DUARTE FILHO, J. Cultivares de morango. In: CARVALHO SP de (coord). Boletim do morango: cultivo convencional, segurança alimentar, cultivo orgânico. Belo Horizonte: FAEMG. 2006.p. 15-22.

; ANTUNES, L. E. C.; PÁDUA, J. G. Introdução e avaliação de cultivares de morangueiro no Sul de Minas Gerais. Horticultura Brasileira, Brasília, v. 21, n. 2, 2003. Suplemento, CD-ROM.

EMBABY, E. M. Pestalotia fruit rot on strawberry plants in Egypt. EgyptJournalPhytopathol., v. 35, n. 2, p. 99 $110,2007$.

FORTES, J. F. Doenças do morangueiro. In: Embrapa Clima Temperado. Sistema de produção do Morango. Pelotas, 2005. Disponível em:

$<$ http://sistemasdeproducao.cnptia.embrapa.br/FontesHTML/Morango/SistemaProducaoMorango/cap06.htm >. Acessoem: 14 out. 2013.

KANUFT, D. A.; GORBET, D. W.; NORDEN A. J. Yield and market quality of seven peanut genotypes as affected by leafspot disease and harvest date. Peanut Science. v.15, p. 9-13, 1988.

LEGARD, D. E. et al. Development of a reduced use fungicide program for control of Botrytis fruit rot on annual winter strawberry. PlantDisease. v. 89, n. 12, p. 1353-1358, 2005.

LIMA, L. C. O. Qualidade, colheita e manuseio pós-colheita de frutos de morangueiro. Informe Agropecuário, Belo Horizonte, v. 20, n. 198, p. 80-83, 1999.

LOPES, U. P. Podridões pós-colheita de morango: etiologia e efeito de produtos alternativos. Viçosa: UFV, 2011. 
55f. Dissertação. (Mestrado em Fitopatologia). Universidade Federal de Viçosa. Viçosa, 2011.

OLIVEIRA, A. C. B.; BONOW, S. Novos desafios para o melhoramento genético da cultura do morangueiro no Brasil. Informe Agropecuário, Belo Horizonte, v. 33, n. 268, p. 21-26, 2012.

OLIVEIRA, R. P.; SCIVITTARO, W. B. Desempenho produtivo de cultivares de morangueiro. Scientia Agrária, Curitiba, v. 12, n. 2, p. 69-74, 2011.

; _ _ _ FINKENAUER, D. Produção de morangueiro da cv. Camino Real em sistema de túnel. Revista Brasileira de Fruticultura, Jaboticabal, v. 30, n. 3, p. 681-684, 2008.

PAGNAN, H. A. Doenças no morangueiro. Campo e Negócios, Uberlândia, v. 8, n.95, p. 74-75, 2013.

; MONEGAT, V. Morango cultivado em substrato ou em semi-hidroponia. Campo e Negócios, Uberlândia, v. 8, n. 105, p. 62-65, 2014.

PEREIRA, C. TEIXEIRA, M.A.; VIEIRA, R.F.; PEREIRA, G,C.; FARIA, J.P. Evaluation of melaleuca sp. oil in the control of Pestalotiopsis longisetula. A phytopatothogenic fungus in strawberry cultivation on field conditions. Holos Environment, Rio Claro, 2011, v. 11, n. 1, p.84, 2011 . Suplemento 1.

PEREIRA, W. R.; SOUZA, R.J.; YURI, J.E.; FERREIRA, S. Produtividade de cultivares de morangueiro, submetidas a diferentes épocas de plantio. Horticultura Brasileira, Brasília, v. 31, n. 3, p. 500-503, 2013.

RADIN, B.; LISBOA BB; WITTER S; BARNI V; REISSER JUNIOR C; MATZENAUER R; FERMINO MH. Desempenho de quatro cultivares de morangueiro em duas regiões ecoclimáticas do Rio Grande do Sul. Horticultura Brasileira, Brasília, v. 29, p. 287-291, 2011.

REIS, A.; COSTA, H. Principais doenças do morangueiro no Brasil e seu controle. Circular Técnica, n. 96, Brasília: Embrapa Hortaliças, 2011. 9p.

SHAW, D. V. Strawberry production systems, breeding and cultivars in Califórnia.In: SIMPÓSIO NACIONAL DO MORANGO, 2.; ENCONTRO DE PEQUENAS FRUTAS E FRUTAS NATIVAS. 1. Anais... Pelotas: EMBRAPA, CLIMA TEMPERADO. p. 15-20, 2004.

ZAMBOLIM, L.; COSTA, H. Manejo integrado de doenças do morangueiro. In: CARVALHO S. P. de (coord). Boletim do morango: cultivo convencional, segurança alimentar, cultivo orgânico. Belo Horizonte: FAEMG. 2006. p. 55-80.

\section{Histórico}

Submetido em: 10/05/2013

Aceito em: 21/05/2014 